TERRA. Revista de Desarrollo Local

e-ISSN: 2386-9968

Número 7 (2020), 315-321

DOI 10.7203/terra.7.19030

IIDL - Instituto Interuniversitario de Desarrollo Local

\title{
Reseña. La España que abandonamos
}

\section{Lidia Espí Verdú}

Graduada en Geografía y Medio Ambiente (Valencia, España) y Máster en Gestión de Desastres (Madrid, España)

lidia.ev96@gmail.com

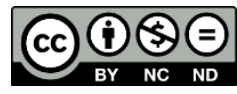

Esta obra se distribuye con la licencia Creative Commons

Reconocimiento-NoComercial-SinObraDerivada 4.0 Internacional 


\section{SECCIÓN RESEÑAS}

\section{Reseña. La España que abandonamos}

Resumen: Esta obra reivindica los espacios rurales como espacios alejados de estereotipos de moda, que requieren respuestas y actuaciones eficaces frente al abandono de actividades y los procesos de despoblación y despoblamiento que muchos de ellos, especialmente los más periféricos, siguen experimentando en pleno siglo XXI. A partir de ocho experiencias repartidas en la mitad septentrional de España, y sintetizadas en 312 páginas, conectamos con las vivencias y recuerdos de los vecinos que se quedaron en esos pueblos o que se marcharon, pero que ahora han vuelto porque siempre anhelaron regresar a su hogar. En este libro no solo se presentan datos, sino que se conecta con la historia real de la despoblación. Y de esta conexión surge la pregunta que la obra intenta responder ¿̇la gente necesita a los pueblos o son los pueblos los que necesitan a la gente?

Palabras clave: Despoblación, espacios rurales, calidad de vida, servicios a la población.

Recibido: 13 de noviembre de 2020

Devuelto para revisión: -

Aceptado: 15 de noviembre de 2020

\section{Referencia / Citation:}

Espí, L. (2020). Reseña. La España que abandonamos. TERRA. Revista de Desarrollo Local, (7), 315-321. DOI 10.7203/terra.7.19030 


\section{Denis Escudero Muñoz}

\section{LA ESPAÑA QUE ABANDONAMOS}

Almería, Editorial Círculo Rojo, 2020 (2da edición), 312 páginas

\section{LA ESPAÑA QUE ABANDONAMOS}

DENIS ESCUDERO MUÑOZ

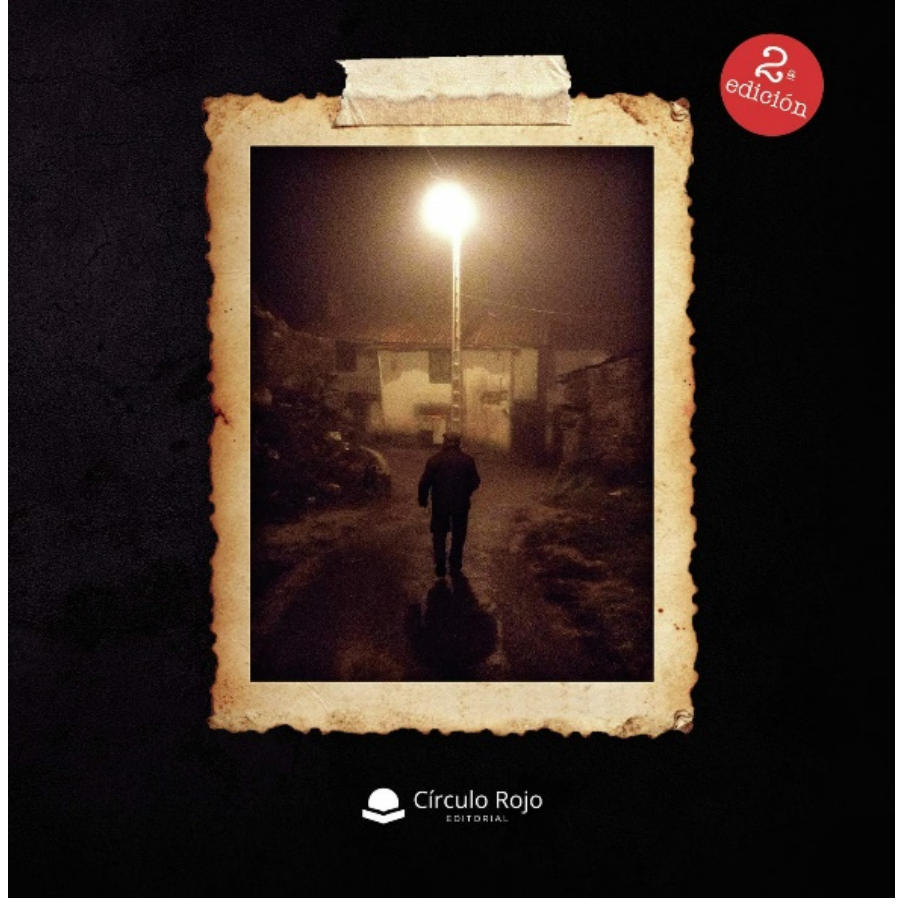

La visión con la que se trata el tema de la despoblación en esta obra es mucho más realista que el derrotismo con el que se ha tratado el tema en otras ocasiones. El autor reivindica dejar atrás los tópicos que tanto daño han hecho a los pueblos afectados por la despoblación, pues son espacios reales que necesitan respuestas y actuaciones eficaces frente a su estado, y no penas ni nostalgias que no aportan nada positivo. Llamar a estos espacios afectados por la despoblación términos como "pueblos fantasma" o incluso "la Siberia del sur de Europa" no ayuda a que se trate el problema que hay en estos territorios, un problema al que se necesita poner atención y solución. Se trata de apartar los estereotipos que hay sobre los pueblos, porque no son buenos. Este libro da voz a los pueblos, a sus vecinos y al futuro que ellos mismos esperan.

En líneas generales, la obra puede ser organizada por parte del lector en tres grandes bloques, siendo en todos ellos las historias de los pueblos visitados las líneas de unión. En primer lugar, en el prólogo el autor nos presenta las ideas fundamentales que le han empujado a realizar este libro. En segundo lugar, contamos con ocho capítulos que corresponden al viaje realizado por el autor por la geografía español, y en donde conocemos mejor las realidades de los pueblos visitados que experimentan, en distinto grado, los conocidos y mediáticos procesos de despoblación, las experiencias de los vecinos y el futuro que en ellos se alberga. Y en tercer lugar, contamos con el epílogo a modo de despedida y reflexión final de esa travesía y esas experiencias. La obra acaba, no obstante, con unos más que merecidos agradecimientos.

El texto presenta a lo largo de sus 312 páginas una redacción que te hace conectar con los territorios visitados y sus historias. En ningún caso se presenta un análisis demográfico o socioeconómico simplista de estos lugares con datos, sino que se aporta mucho más, porque nos hace adentrarnos en las experiencias y recuerdos de sus habitantes actuales, pero sin perder la realidad actual. Realidad-es muy duras que son explicadas por los mismos vecinos que se quedaron en esos pueblos o que se marcharon, pero que ahora han 
vuelto porque siempre anhelaron regresar a su hogar. En este libro no solo se presentan datos, sino que se conecta con la historia real de la despoblación.

Sabemos que estos espacios rurales se enfrentan a un reto demográfico muy complicado, la población está envejecida y ya no hay relevo generacional. No obstante, aunque el tema de la despoblación es actual, los vecinos de estos pueblos protestan por el abandono que han sufrido durante tantos años, porque para ellos son las administraciones las que han facilitado el vaciamiento de estos espacios y la concentración de las ciudades. Ahora se necesitan políticas de gestión efectivas para todos los municipios afectados por el fenómeno de la despoblación, y son los habitantes los que lo reclaman.

El autor visita ocho municipios que se encuentran en las zonas con mayor despoblación del territorio español: Trevejo (Extremadura), Portalrubio de Guadamejud (Castilla-La Mancha), La Estrella (Aragón), Jánovas (Aragón), Castillonuevo (Comunidad Foral de Navarra), Villarroya (La Rioja), Valtarejos (Castilla y León) y Jaramillo Quemado (Castilla y león). Entre todos los censos de población de estos ocho pueblos suman 84 personas empadronadas para 2019.

Figura 1. Pueblos visitados en la obra por el autor

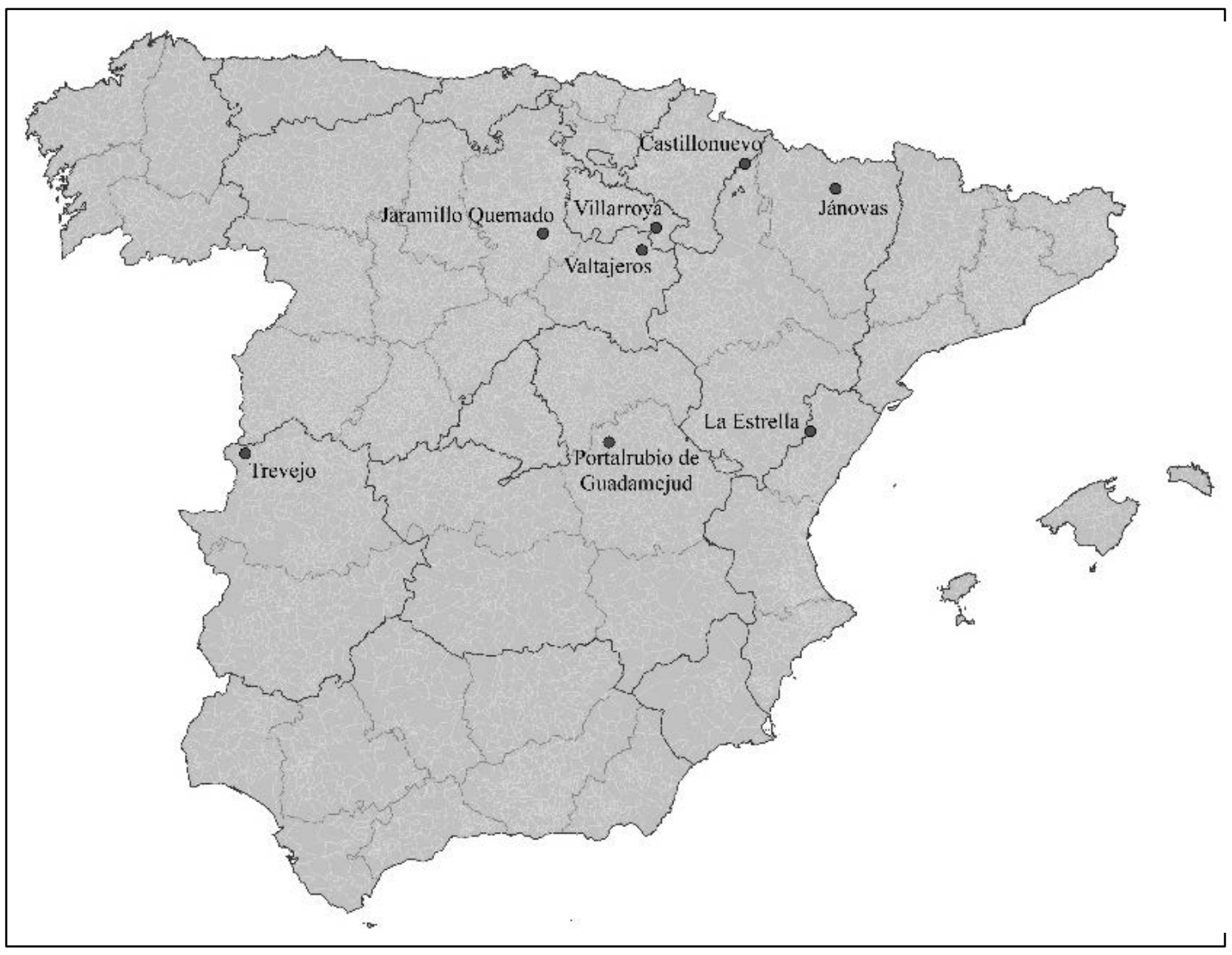

Fuente: elaboración propia.

El primero de los pueblos visitados es Trevejo, situado al norte de Cáceres y que cuenta con 17 personas empadronadas, aunque no todas viven durante todo el año. Este pueblo ha mejorado mucho durante las últimas décadas, ahora las carreteras son buenas y hasta 
hay casas de turismo rural. Además, el bar está abierto, y esto es muy importante para sus vecinos ya que tiene un gran valor social porque hace de conexión entre la gente.

El segundo de los pueblos visitados es Portalrubio de Guadamejud (Cuenca) que ha sido siempre tierra de agricultores y ganaderos; actualmente tiene a 27 habitantes empadronados y es famoso por su "Mural contra la despoblación”, y otras acciones reactivas y reivindicativas por parte de sus vecinos. El centro sociocultural juega un papel muy importante en esta localidad, es donde la asociación del pueblo se junta para organizar y luchar contra la despoblación y abandono.

El tercer lugar visitado es La Estrella, también conocido como la Villeta, un pueblo muy especial que cuenta con tan solo dos vecinos desde hace más de 35 años, el matrimonio compuesto por Sinforosa y Juan. Este municipio de la provincia de Teruel forma parte del ayuntamiento de Mosqueruela, y aunque son bastantes los excursionistas que visitan el pueblo, el pueblo está abandonado. No obstante estos vecinos nos dan un gran ejemplo de que "lo que se cuida, se mantiene", y es que si los pueblos se cuidaran de la misma manera que Sinforosa y Juan han cuidado el santuario del pueblo, "otro gallo cantaría”.

El cuarto de los pueblos visitados es Jánovas, una localidad de la provincia de Huesca que pertenece al ayuntamiento del municipio de Fiscal. Este pueblo es ejemplo de resistencia, y aunque ahora no hay nadie viviendo en él, está en plena recuperación tras la expropiación forzosa que sufrieron en los años 50 por un proyecto fallido de Iberduero para generar energía eléctrica. Ahora la antigua escuela es el centro social donde se juntan los vecinos para organizarse y poder recuperar su pueblo, un pueblo del que fueron expulsados incluso antes del éxodo rural.

El quinto de los pueblos visitados es Castillonuevo, un pueblo situado al norte de la Comunidad Foral de Navarra que limita con Aragón, y que actualmente cuenta con 17 habitantes empadronados. Es el municipio con menos habitantes y con la densidad de población más baja de Navarra, y durante todo el año solo vive una persona, su alcalde. Este pueblo está en un estado de conservación magnífico, pero no tiene vecinos que llenen sus calles. Todos repiten una y otra vez que el motivo principal por el que no se puede vivir en el pueblo es porque no hay trabajo para la gente, pero también hacen mucho hincapié en la responsabilidad que la administración tiene con estos espacios rurales.

El sexto de los pueblos visitados es Villarroya, la localidad con menos habitantes de la Rioja. Es un municipio independiente de Arnedo desde 1789 que cuenta con ocho personas empadronadas, cuya economía siempre dependió de la agricultura, la ganadería, y de la minería. No obstante, aunque la minería les dio trabajo y dinero, también fue la responsable de la expulsión de la población. Y es que además de que la actividad minera empezó a crear fracturas en la localidad, la empresa responsable forzó la expropiación de las casas, proceso que provocó la salida de los vecinos. No obstante, ahora después de tantos años, la gente del pueblo está luchando para que el pueblo no muera y se recupere. En esta localidad el sentimiento de pueblo y de comunidad es tan grande, tienen tantas ganas de continuar su historia y mantener sus raíces, que el futuro está casi asegurado.

El séptimo de los pueblos visitados es Valtarejos, un municipio situado en la comarca de Soria que cuenta con 19 personas empadronadas, aunque son seis las personas que viven todo el año. Los tópicos en este pueblo han hecho mucho daño: hablar del frío de invierno y las duras condiciones de vida de aquí no han ayudado ni a que volviera la gente que se marchó hace años, ni tampoco que llegue gente nueva a vivir. Los vecinos destacan que 
el papel de las plataformas es clave para estos territorios a los que se les ha facilitado la pérdida de gente y de servicios. Ahora hay acceso a internet, hay turismo, hay calidad de vida... hay de todo menos personas que quieran vivir todo el año en el pueblo, porque de momento la gente joven que está en el pueblo lo ve como un espacio de descanso u ocio de fin de semana.

Y, por último, el octavo de los pueblos visitados es Jaramillo Quemado, el municipio más pequeño con ayuntamiento propio de España. Se encuentra en la provincia de Burgos y en los últimos años han pasado de ser cuatro personas en el censo a ser un total de siete personas. Luchan por resistir, y reivindican que la despoblación, aunque sea un tema de actualidad, no es producto del presente sino del pasado. Parece que el futuro de los pueblos sea el turismo, el ocio o el descanso, pero debe ser mucho más. Los vecinos de este pueblo han añorado mucho su pueblo, y por eso han vuelto, porque lo han valorado y quieren estar ahí.

El autor nos presenta su teoría sobre las edades de retorno a los pueblos: "de niños nos encantan, después pasamos más de media vida obviándolos y a partir de los cincuenta volvemos a añorarlos”. Y hace reflexionar a los vecinos de los pueblos qué de cierto hay en todo eso.

Para los pueblos, los fines de semana, las vacaciones de verano y las festividades son fechas clave porque su población se multiplica. Los entrevistados destacan la importancia de que la gente siga volviendo al pueblo, aunque solamente sea en fechas clave, porque eso significa que no olvidan su tierra y sus raíces, y eso ayuda a no perder la esperanza. Cuando se habla con los vecinos de qué es aquello que les da el pueblo, se coindice en todos los casos: el pueblo es sinónimo de libertad, de calidad de vida y de una infancia feliz. Libertad e independencia, porque en las ciudades se han sentido esclavos del tiempo y las distancias, y en su pueblo se sienten libres. También hablan de la calidad de vida que hay en los pueblos, ahora mucho mejor que antiguamente: ya no hay frío, las calles están asfaltadas, tienen agua, luz e internet, e incluso infraestructuras totalmente nuevas que antes no tenían.

La infancia que recuerdan todos es feliz, y la comparan en la actualidad con la de sus hijos cuando están en el pueblo, con esa libertad y todo el tiempo del mundo para disfrutar las calles, los campos y el cariño que se respira siempre. Pero por otro lado, es necesario cuidar a los pueblos, a sus ayuntamientos, y facilitar el regreso y el posicionamiento de nuevas actividades socioeconómicas en ellos, porque sin trabajo es muy difícil mantenerlos. Y es que la razón principal que destacan los vecinos es la falta de trabajo y oportunidades que hay en estos lugares, además de la pérdida de servicios como colegios, médicos, farmacias o tiendas.

Mantener el ayuntamiento, tener bar en el pueblo, contar con asociaciones y plataformas locales, el papel de la gestión pública y la administración, la falta de trabajo, el papel del turismo, la dispar visión de los jóvenes frente a la de los mayores, pero sobre todo la visión futura de los pueblos, de sus pueblos. Todos estos temas son tratados de forma personal y analizados por los vecinos de estos ocho municipios.

Durante todo su viaje el autor lanza una cuestión que nos hacen reflexionar mucho: “¿La gente necesita a los pueblos o son los pueblos los que necesitan a la gente?’. Y durante todo el viaje nos damos cuenta de que son los pueblos los que necesitan a la gente, porque los pueblos son sus gentes. Y porque los pueblos tienen ganas de vivir, y no se puede vivir solo de los recuerdos del pasado. 
Lidia Espí Verdú

Graduada en Geografía y Medio Ambiente, Universitat de València

Máster en Gestión de Desastres, Universidad Complutense de Madrid y la Universidad

Politécnica de Madrid 